\title{
Analiza učinaka Bobath tretmana i klasičnoga fizioterapijskog tretmana u aktivnostima svakodnevnog života kod bolesnika nakon moždanog udara Barthelovim indeksom
}

1 Martina Cipan

1 Gordana Grozdek Čovčić

1 Mirjana Telebuh

1 Zdravstveno veleučilište Zagreb

\section{Sažetak}

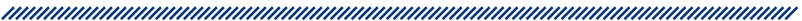

Uvod: Moždani je udar među vodećim uzrocima smrtnosti i invalidnosti u svijetu, a prvi je uzrok invalidnosti u Republici Hrvatskoj. Kao posljedica moždanog udara nastaje različiti stupanj tjelesnog, kognitivnog i psihosocijalnog poremećaja. Bolesnicima je najteža posljedica nakon moždanog udara gubitak sposobnosti obavljanja aktivnosti svakodnevnog života i ovisnost o tuđoj pomoći. Oporavak bolesnika ovisi o vrsti moždanog udara, mjestu zahvaćenosti te težini onesposobljenosti, potpori obitelji i održavanju postojećeg stanja. Primarni je cilj neurorehabilitacije funkcionalni napredak kroz maksimalno moguće vraćanje neovisnosti životnog funkcioniranja. Za što uspješniju rehabilitaciju nužno je aktivno sudjelovanje obitelji bolesnika, specifična edukacija osoblja te rani početak rehabilitacije.

Cilj: Cilj provedenog istraživanja bio je ispitati učinkovitost Bobath tretmana i klasičnog fizioterapijskog tretmana na obavljanje aktivnosti svakodnevnog života kod bolesnika nakon moždanog udara.

Materijali i metode: $U$ istraživanje je uključeno 30 ispitanika koji su podijeljeni unutar dvije eksperimentalne skupine. Osnovni kriterij za odabir ispitanika bila je prisutnost moždanog udara. Prva eksperimentalna skupina E1 tretirana je klasičnim fizioterapijskim tretmanom, dok je druga eksperimentalna skupina E2 tretirana Bobath tretmanom. Obje skupine bile su tretirane kroz 15 dana, unutar tri tjedna, a tretman je trajao 45 minuta dnevno. Procjena aktivnosti svakodnevnog života mjerena je standardiziranim Barthelovim indeksom, a provedena je na početku i na kraju tretmana.

Rezultati: Istraživanje je pokazalo kako učinci klasičnog fizioterapijskog tretmana i Bobath tretmana nisu statistički značajni. Prema dobivenim rezultatima Barthel indeksa vidljivo je da Bobath tretman ima veći učinak na poboljšanje obavljanja aktivnosti svakodnevnog života kod bolesnika nakon moždanog udara za razliku od klasičnog fizioterapijskog tretmana, no statistički to nije potvrđeno.

Zaključak: Rezultati između inicijalnih i završnih mjerenja u obje skupine ispitanika nisu pokazali statistički značajne učinke u obavljanju aktivnosti svakodnevnog života, iako rezultati ukazuju na pozitivnu tendenciju obje skupine u samostalnosti obavljanja aktivnosti svakodnevnog života, posebno u drugoj skupini ispitanika.

Ključne riječi: moždani udar, aktivnosti svakodnevnog života, neurorehabilitacija, Barthelov indeks

Datum primitka: 07.10.2016.

Datum prihvaćanja: 01.06.2017.

DOI: $10.24141 / 3 / 1 / 5$

Adresa za dopisivanje:

Martina Cipan

Slave Raškaj, 3, 43500 Daruvar

E-pošta: Martina.Cipan@zvu.hr

Tel.: +385914595741 


\section{UVOD}

Moždani je udar među prva tri uzroka smrtnosti u svijetu, prvi uzrok invalidnosti i važan uzrok demencije i depresije. U Republici Hrvatskoj moždani udar posljednjih je godina vodeći uzrok smrtnosti i vodeći uzrok invalidnosti. Analiza po dobi pokazuje da broj umrlih i dobno specifične stope smrtnosti od moždanog udara rastu s dobi, a izrazitiji porast zabilježen je nakon 50 . godine života. ${ }^{1}$ Iz tih je podataka vidljivo da je moždani udar velik problem u starijoj životnoj dobi.

Moždani udar daje visok mortalitet i visok stupanj invaliditeta. Oko polovice svih preživjelih vrati se nekom zaposlenju, a 25 do $30 \%$ nije sposobno funkcionirati bez pomoći druge osobe, ${ }^{2}$ što najviše zabrinjava bolesnike te dovodi do nastajanja psiholoških problema i problema socijalne integracije. ${ }^{3}$

Zahvaljujući promijenjenom načinu života i smanjenju faktora rizika, boljem zbrinjavanju bolesnika, kako u primarnoj i sekundarnoj prevenciji tako i u akutnoj fazi, incidencija se moždanog udara u razvijenim zemljama smanjila, a mortalitet reducirao. Nažalost, manje razvijene zemlje, kao i zemlje u tranziciji, kojima pripada i Hrvatska, nisu podložne takvim promjenama. Podatci za Hrvatsku pokazuju stalan porast pobola i mortaliteta nakon moždanog udara. ${ }^{4}$

Problemi su koji se javljaju kao onesposobljenost kod bolesnika nakon moždanog udara: oduzetost dijelova tijela, manja ili veća ovisnost u aktivnostima svakodnevnog života, promjene mišićnog tonusa, oštećenje balansa, govora, osjeta i pamćenja te emocionalne smetnje.

Primarni je cilj neurorehabilitacije nakon moždanog udara funkcionalni napredak kroz maksimalno moguće vraćanje neovisnosti životnog funkcioniranja. ${ }^{5,6}$ Kao posljedica moždanog udara zaostaje različiti stupanj fizičkog, kognitivnog i psihosocijalnog poremećaja. Oporavak bolesnika ovisi o težini onesposobljenosti, o programu rehabilitacije, ali i o kasnijem održavanju postignutih funkcija, kao i o njezi i potpori obitelji i okoline. Za što uspješniju rehabilitaciju nužno je aktivno sudjelovanje obitelji bolesnika, specifična edukacija osoblja, rani početak rehabilitacije ${ }^{7}$ i intenzitet rehabilitacije. Rana rehabilitacija uvelike poboljšava funkcionalni oporavak te smanjuje broj bolesnika ovisnih o tuđoj pomoći. lesnicima što veću neovisnost i samostalnost u aktivnostima svakodnevnog života, odnosno vratiti ih ranijim svakodnevnim aktivnostima.

\section{METODE RADA}

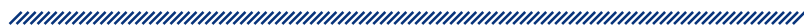

Cilj provedenog istraživanja bio je ispitati učinkovitost klasičnoga fizioterapijskog tretmana i Bobath tretmana na obavljanje aktivnosti svakodnevnog života kod bolesnika nakon moždanog udara Barthelovim indeksom te ispitati postoji li znatna razlika u učinkovitosti tih dvaju tretmana.

Za istraživanje je odabran mali, prigodni uzorak koji čine bolesnici uključeni u proces stacionarne neurorehabilitacije na neurološkom odjelu Specijalne bolnice za medicinsku rehabilitaciju Lipik. Bolesnici su u istraživanje uključivani prigodno, prema slijedu dolaska na rehabilitaciju u navedenu ustanovu u skladu s unaprijed određenim kriterijima uključivanja.

Prilikom odabira ispitanika za istraživanje, bolesnici su informirani o mogućnosti njihova uključivanja u istraživanje i tražen je njihov usmeni pristanak, ali nisu bili upoznati s ciljem istraživanja radi sprječavanja utjecaja na rezultate.

$\mathrm{U}$ istraživanje je bilo uključeno ukupno 30 ispitanika podijeljenih u dvije eksperimentalne skupine. Osnovni kriterij za odabir ispitanika bila je prisutnost moždanog udara. $\mathrm{U}$ istraživanje su uključeni bolesnici nakon ishemijskog i hemoragijskog moždanog udara, koji su u kliničkoj slici imali hemiparezu, neovisno koje strane tijela.

Uzorak uključuje ispitanike različitog spola, 20 muškaraca i 10 žena, različite lateralizacije pogođenosti strana tijela nakon CVI-a, u dobi od 57 do 85 godina.

Prva eksperimentalna skupina ispitanika E1 uključivala je 15 ispitanika tretiranih klasičnim fizioterapijskim tretmanom koji je uključivao klasični tretman medicinske gimnastike (vježbe jačanja muskulature, vježbe istezanja, vježbe ravnoteže i slično) u trajanju od 30 minuta i trening hoda u trajanju od 15 minuta, pet puta tjedno kroz tri tjedna.

Klasični fizioterapijski tretman uključivao je vježbe gdje se ovisno o procjeni bolesnika radi na povećanju op- 


\begin{tabular}{|c|c|c|c|c|}
\hline \multicolumn{4}{|c|}{ Tablica 1. Prikaz i raspodjela ispitanika prema spolu i dobi za obje skupine ispitanika (E1, E2) } \\
\hline & Spol & Broj ispitanika & Raspon dobi & Prosječna dob \\
\hline \multirow{2}{*}{$\begin{array}{c}\text { Klasični fizioterapijski } \\
\text { tretman - E1 }\end{array}$} & muškarci & 11 & $60-63$ & 72,55 \\
\hline \multirow{2}{*}{ Bobath tretman - E2 } & žene & 4 & $68-85$ & 62 \\
\hline & muškarci & 9 & $57-76$ & 62,11 \\
\hline
\end{tabular}

sega pokreta, jačanju muskulature, istezanju mišića i mobilizaciji zglobova. Cilj je klasičnoga fizioterapijskog tretmana brže postizanje samostalnosti. Uz vježbe, klasični fizioterapijski tretman obuhvaća i školu hoda gdje se bolesnik maksimalno koristi aktivnošću nezahvaćene ruke i noge. Škola ili trening hoda sastoji se od vježbi na pokretnoj traci, vježbi hoda sa suspenzijskom potporom težine tijela, potpomognutim hodom od strane fizioterapeuta ili hodom uz pomagalo, ovisno o fizioterapijskoj procjeni bolesnika te o mogućnostima prostora u kojem se tretman odvija.

Druga eksperimentalna skupina E2 uključivala je 15 ispitanika tretiranih po metodi Bobath. tretman su provodili educirani Bobath terapeuti koji su naglasak unutar terapije davali na mobilizaciju skapule i facilitaciju gornjih ekstremiteta, 45 minuta dnevno, pet puta tjedno kroz tri tjedna.

Bobath tretman/koncept jest neurofacilitacijski pristup utemeljen na znanstvenim spoznajama u čijem je fokusu holistički pristup pacijentu i njegovim motoričkim i ostalim problemima, sprječavanje kompenzacija, facilitacija normalnog oblika pokreta i svakodnevnih motoričkih aktivnosti, ${ }^{10}$ a razvoj se temelji na direktnom radu terapeuta s pacijentima te stalnom usavršavanju i primjeni novih vještina i spoznaja. Bobath tretman pristup je u kojem terapeut, koristeći se aferentnim informacijama, može utjecati na središnji živčani sustav bolesnika stimulirajući reorganizaciju strukture i funkcije, stvaranje novih sinapsi i nicanje dendrita. Stručno specijalizirani fizioterapeuti primjenjuju aferentni unos informacija za ponovno educiranje bolesnika u cilju što normalnijeg obrasca pokreta, veće učinkovitosti pokreta u funkcionalnom smislu, odnosno veće mogućnosti pokreta. ${ }^{11}$

Na početku tretmana kroz inicijalno mjerenje, kao i na kraju tretmana kroz finalno mjerenje, kod ispitanika obje skupine procjenjivao se stupanj neovisnosti u aktivnostima svakodnevnog života standardiziranim upitnikom, Barthelovim indeksom. ${ }^{12}$ Procjena Barthelovom ljestvicom između pet i devet dana nakon moždanog udara pokazuje se kao optimalno razdoblje za stvaranje prognoze za konačan ishod aktivnosti svakodnevnog života, u svrhu planiranja programa rane rehabilitacije. ${ }^{13}$

Test aktivnosti svakodnevnog života izvodi se Barthelovim indeksom i njime se testiraju aktivnosti u krevetu, aktivnosti u invalidskim kolicima, aktivnosti samozbrinjavanja, aktivnosti kretanja i penjanja po stepenicama.

Rezultat Barthelova indeksa kreće se od 0 do 100, a bodovi se tumače kao:

- 0 do 20 - potpuna ovisnost

- 21 do 60 - teška ovisnost

- 61 do 90 - umjerena ovisnost

- 91 do 99 - laka ovisnost

- 100 - samostalna osoba u svim aspektima svakodnevnog života.

Testiranje aktivnosti svakodnevnog života izvodi se pri prijmu bolesnika na hospitalizaciju i pri otpustu, a služi i kao evaluacijski pokazatelj rehabilitacijskog tretmana. ${ }^{14}$

Mnogi autori smatraju da ako je rezultat Barthel indeksa niži od 40, bolesnici imaju manju vjerojatnost da budu samostalni, ${ }^{15}$ a Grangera i suradnici smatraju da kod $70 \%$ bolesnika bolest završava smrću ako imaju rezultat Barthela manji od 40. ${ }^{16}$

Barthelov je indeks uz Functional measure scale (FIM indeks) najčešće mjerilo samostalnosti pacijenata. Dvije ljestvice za evaluaciju ASŽ-a (Barthelov indeks, FIM indeks), iako zahtijevaju više vremena za provođenje, imaju pojačanu senzitivnost, što ih čini vrlo učinkovitima, dopuštajući i manjim komponentama da budu obuhvaćene. ${ }^{17}$ 


\section{REZULTATI ISTRAŽIVANJA}

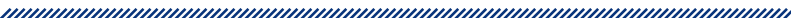

Učinak tretmana prikazuje se kroz razliku aritmetičke sredine $(x)$ između prvog inicijalnog i drugog finalnog mjerenja kod prve i druge eksperimentalne skupine. Ako je aritmetička sredina veća, učinak je tretmana veći.

Dobiveni rezultati prvog i drugog mjerenja Barthelovim indeksom (tablica 2), prikazuju veću razliku aritmetičkih sredina u drugoj eksperimentalnoj skupini tretiranoj Bobath tretmanom.

Razlike učinaka fizioterapeutskih postupaka između dviju eksperimentalnih skupina izražene su razlikom njihovih aritmetičkih sredina i statistički su testirane ttestom. Značajnost razlika aritmetičkih sredina mjerene varijable testirana je t-testom za male zavisne uzorke, a rezultati su prikazani u tablici 3.

Rezultati vidljivi iz tablice 3 ukazuju na to da ne postoji statistički značajna razlika između inicijalnog i završnog mjerenja svih ispitanika u obje ispitivane grupe po Barthelovom indeksu.

Rezultati t-testa pokazuju da nijedan tretman ne daje statistički značajan učinak na poboljšanje obavljanja aktivnosti svakodnevnog života ispitivanog Barthelovim indeksom (tablica 3). Međutim, vidljivo je da je u drugoj ispitivanoj skupini E2 razlika između aritmetič- kih sredina inicijalnog i finalnog mjerenja blizu statističke značajnosti ( $p=0,072)$, što ide u prilog tendenciji boljeg učinka tretmana prema Bobath konceptu u odnosu na ispitanike tretirane klasičnim fizioterapijskim tretmanom.

Rezultati dobiveni u ovom radu mogu se potkrijepiti i ostalim sličnim istraživanjima. Tako istraživanje Mikolajewske ukazuje na statistički značajne i povoljne razlike u rezultatima procjene nakon primjene Bobath tretmana kao rehabilitacije nakon moždanog udara i procjeni hoda, aktivnostima svakodnevnog života i funkcije ruku, ali postoji pretpostavka da je teško postići istovremeni oporavak u svim područjima koja želimo poboljšati. ${ }^{18}$ Usmjerenost na pojedinu aktivnost pri tretmanu od velike je važnosti u postizanju poboljšanja upravo kod aktivnosti svakodnevnog života.

\section{ZAKLJUČAK}

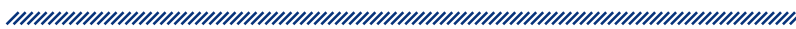

Zastupljenost muškaraca i žena u ovom istraživanju potvrđuje mnoga istraživanja drugih autora. Lavados i suradnici naveli su da je među bolesnicima s moždanim udarom bilo $56 \%$ muškaraca i $44 \%$ žena. ${ }^{19}$

\begin{tabular}{|c|c|c|c|c|}
\hline \multicolumn{5}{|c|}{ Tablica 2. Prikaz razlika aritmetičkih sredina i standardne devijacije, } \\
za prvu (E1) i drugu (E2) ispitivanu skupinu \\
\hline \multirow{2}{*}{$\begin{array}{c}\text { Klasični fizioterapijski tretman } \\
\text { - E1 }\end{array}$} & Skupina & N & X & Stand. dev \\
\cline { 2 - 5 } & INIC & 15 & 59,93 & 24,132 \\
\hline \multirow{2}{*}{ Bobath tretman-E2 } & FINAL & 15 & 72,33 & 22,576 \\
\cline { 2 - 5 } & INIC & 15 & 64,53 & 23,880 \\
\hline
\end{tabular}

\begin{tabular}{|c|c|c|c|c|}
\hline & Skupine & $\mathrm{t}$ & df & $\mathrm{p}$ \\
\hline \multirow{2}{*}{ Barthel } & $\begin{array}{c}\text { Klasični fizioterapijski } \\
\text { tretman - E1 }\end{array}$ & $-1,453$ & $\begin{array}{c}28 \\
27,876\end{array}$ & 0,157 \\
\hline & Bobath tretman - E2 & $-1,869$ & $\begin{array}{c}28 \\
27,811\end{array}$ & 0,072 \\
\hline
\end{tabular}


Provedeno istraživanje potvrđuje i tendenciju da od moždanog udara obolijevaju u prvom redu starije osobe, međutim od ukupnog broja moždanih udara $28 \%$ bolesnika mlađe je od 65 godina. ${ }^{20}$

Rezultati između inicijalnih i završnih mjerenja u obje skupine ispitanika nisu pokazali statistički značajne učinke u obavljanju aktivnosti svakodnevnog života, iako rezultati ukazuju na pozitivnu tendenciju obje skupine u samostalnosti obavljanja aktivnosti svakodnevnog života.

Pozitivniji rezultati u eksperimentalnoj skupini tretiranoj po Bobath tretmanu mogli bi se objasniti činjenicom da je u Bobath pristupu naglasak bio na mobilizaciji i facilitaciji trupa te mobilizaciji i facilitaciji skapule i gornjih ekstremiteta, u odnosu na eksperimentalnu skupinu tretiranu klasičnim fizioterapijskim pristupom, gdje je uz klasične vježbe primjenjivan trening hoda kod bolesnika nakon moždanog udara.

Na temelju ovog istraživanja zaključeno da nijedan od tretmana nije statistički značajan, iako je tendencija rezultata prema značajnosti bio tretman prema Bobathu u drugoj ispitivanoj skupini. Čimbenik utjecaja na neznačajnost rezultata može biti i nehomogenost skupina po spolu i po dobi, kao i mala veličina uzorka.

U budućim istraživanjima bilo bi dobro povećati broj ispitanika u uzorku te bi skupine trebale biti homogenije po spolu i po dobi.

\section{LITERATURA}

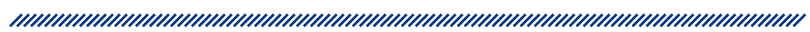

1. Demarin V. Najnovije spoznaje u prevenciji, dijagnostici i liječenju moždanog udara u starijih osoba. Medicus. 2005; 14,2: 219-228

2. Mandić M. Funkcionalni oporavak pacijenata sa hemiparezom posle cerebrovaskularnog insulta različite etiologije. Medicinski Pregled. 2012; (4): 158-162.

3. Van de Port IG, et al. Susceptibility to deterioration of mobility long-term after stroke: a prospective cohort study. Stroke. 2006; 37(1): 167-171.

4. Demarin V. Moždani udar - rastući medicinski i socijalno ekonomski problem. Acta Clinica Croatica. 2004; 43(1): 9-141.

5. Gjelsvik BEB. The Bobath Concept in Adult neurology. Stuttgart: Thieme; 2008.

6. Grozdek Čovčić G, Maček Z. Neurofacilitacijska terapija. Zagreb: Zdravstveno veleučilište; 2011.
7. Warlow C, Sudlow C. et al. Stroke. Lancet. 2003; 362: 1211-1224.

8. Demarin V. Najnovije spoznaje u prevenciji, dijagnostici i liječenju moždanog udara u starijih osoba. Medicus 2005; (14)2: 219-228.

9. Bašić Kes V, Demarin V, et al. Moždani udar. Zagreb: Medicinska naklada; 2014.

10. Paeth Rohlfs B. Erfahrungen mit dem Bobath Koncept. Stuttgart - New York: Thieme; 1999: 45.

11. Graham JV, et al. The Bobath concept in contemporary clinical practice. Topics in stroke rehabilitation. 2009; 16(1): 57-68.

12. Bukilica S, Slavić V, Delić M, Ćirković M, Antić Z. Barthelov indeks - pokazatelj uspješnosti rehabilitacije. Fizikalna $i$ rehabilitacijska medicina. 2012; 24(Suppl 1): 1-250.

13. Kwakkel G. et al. Diagnostic accuracy of the Barthel index for measuring activities of daily living outcome after ischemic hemispheric stroke: does early poststroke timing of assessment matter? Stroke. 2011; 42(2): 342-346.

14. Kapidžić-Duraković S, Bratovčić V. Funkcionalna testiranja osoba nakon moždanog udara. Prvi kongres medicine rada BIH. Dostupno na: http://www.zdravstvo.com/medrada/radovi/kapidzic.htm (pristupljeno 5. kolovoza 2015.).

15. Nakao S, Takata S, Uemura H, Kashihara M, Osawa T, Komatsu K, et al. Relationship between Barthel Index scores during the acute phase of rehabilitation and subsequent ADL in stroke patients. The Journal of Medical Investigation. 2010; 57: 81-88.

16. Granger CV, Hamilton BB, Gresham GE, Kramer AA. Stroke rehabilitation outcomes study: part I. general description. Archivs of Physical Medicine and Rehabilitation. 1989; 69(7): 506-509.

17. Dromerick AW, et al. Sensitivity to changes in disability after stroke: a comparison of four scales useful in clinical trials. Journal of rehabilitation research and development. 2003; Jan-Feb 40(1): 1-8.

18. Mikolajewska E, Associations between results of poststroke NDT-Bobath rehabilitation in gait parameters, $\mathrm{ADL}$ and hand functions. Advance in Clinical and Experimental Medicine. 2013; 22(5): 731-738.

19. Lavados MP, Sacks C, Prina L, Escobar A, Tossi C. Araya $\mathrm{F}$, et al. Incidence, case-fatality rate, and prognosis of ischameic stroke subtipes in a predominantly HispanicMestizo population in Iquiqe, Chile: a community-based incidence study. The Lancet Neurology. 2007; 6: 140-148.

20. Kollen B, Kwakkel G, Lindeman E, Functional recovery after stroke: a review of current developments in stroke rehabilitation research. Reviews on Recent Clinical Trials. 2006; 1: 75-80. 


\section{ANALYSIS OF EFFECTS OF BOBATH TREATMENT AND CLASSIC PHYSIOTHERAPY TREATMENT ON ACTIVITIES OF DAILY LIVING IN PATIENTS AFTER STROKE}

1 Martina Cipan

1 Gordana Grozdek Čovčić

1 Mirjana Telebuh

1 University of Applied Health Sciences, Zagreb

\section{Abstract}

Introduction: Stroke is among the leading causes of mortality and disability, and the first in disability in the Republic of Croatia. The consequences of a stroke may include different degrees of physical, cognitive and psychosocial disorders. The most severe consequence is the loss of ability to perform activities of daily living and dependence on help from the others. The recovery of the patient depends on the type of stroke, the area that has been affected and the severity of disability, family support, and maintaining the status quo.

The primary objective of neurorehabilitation is functional progress through maximum possible regaining of independence in performing daily activities. In order for rehabilitation to be as effective as possible active participation from the patient's families, staff specific training and early start of rehabilitation are necessary.

Aim: The aim of the study was to examine the effectiveness of Bobath treatment and classic physiotherapy treatment on the performance of activities of daily living in patients after the stroke.

Materials and methods: The study included 30 respondents which were divided in two experimental groups.
The basic criteria for the selection of respondents was that they all suffered a stroke. The first experimental group (E1) underwent traditional physiotherapy treatment, and the second experimental group (E2) underwent the Bobath treatment. Both groups were treated for 15 days, within the period of three weeks, and the treatment lasted for 45 minutes per day. The evaluation of activities of daily living was carried out by using the standardized Barthel index, at the beginning and end of the treatment.

Results: The results of the study showed that the effects of classical physiotherapy treatment and Bobath treatment are not statistically significant. The results of the Barthel index show that Bobath treatment has a greater impact on improving the performance of activities of daily living in patients after the stroke $(E 2 x=15.6)$, than in classical physiotherapeutic treatment $(E 1 x=12.44)$, but this has not been statistically confirmed.

Conclusion: The results between initial and final measurements in both groups did not show any statistically significant effects on the activities of daily living, although the results indicate a positive tendency of both groups to be independent of performing daily life activities, especially in the second group of respondents.

Keywords: stroke, activities of daily living, neurorehabilitation, Barthel Index 